\title{
Sistem Pakar Untuk Mendiagnosa Gangguan Kesehatan Mental Menggunakan Algoritma Genetika
}

\author{
Daniel Dwi Kurnia $^{1}$, Septi Andryana ${ }^{2}$, Aris Gunaryati ${ }^{3}$ \\ Universitas Nasional, Informatika, Fakultas Teknologi Komunikasi dan Informatika \\ Jl. Sawo Manila, Pejaten, Pasar Minggu, Jakarta Selatan 12520 \\ e-mail : '1anieldwikurnia@gmail.com, ${ }^{2}$ septi.andryana@civitas.unas.ac.id, \\ 3aris.gunaryati@civitas.unas.ac.id
}

\begin{abstract}
Abstrak
Sehat atau tidaknya hidup seseorang bukan hanya bergantung pada tubuh, melainkan juga pada mental. Agar memiliki kehidupan yang baik harus menjaga keseimbangan kesehatan fisik dan menttal. Banyak orang yang tidak memperdulikan kesehatan mental diri sendiri dan orang di sekitarnya, sampai tidak dapat menyelamatkan nyawa. Depresi, melukai diri sendiri dan bunuh diri adalah salah satu akibat dari gangguan kesehatan mental. Gangguan kesehatan mental (Mental Health Disorder) antara lain Skizofrenia, Depresi, Post Traumatic Stress Disorder (PTSD), Bipolar, Paranoid dan lain sebagainya. Berdasarkan permasalahan yang ada, penulis melakukan perancangan sebuah aplikasi sistem pakar berbasis website. Perancangan sistem pakar ini dengan mamakai bahasa pemrograman PHP dan database MySQL dengan menggunakan algoritma genetika. Algoritma genetika adalah metode yang dapat memberikan solusi dalam memecahkan masalah heuristik dan banyak digunakan untuk pemecahan masalah optimasi. Algoritma genetika yang digunakan adalah Certainty Factor. Hasil pengujian sistem yang telah dilakukan terhadap 20 kasus percobaan menyatakan 85\% sesuai dengan hasil yang diharapkan oleh data pakar. Pembuatan aplikasi tersebut yang diharapkan akan mempermudah mendiagnosa gangguan kesehatan mental pada seseorang.
\end{abstract}

Kata kunci: Website, Sistem Pakar, Genetika, Certainty Factor.

\begin{abstract}
Healthy or not a person's life depends not only on the body, but also on the mental. In order to have a good life one must maintain a balance of physical and mental health. Many people do not care about the mental health of themselves and those around them, to the point of not being able to save lives. Depression, self-harm and suicide are among the consequences of mental health disorders. Mental health disorders include schizophrenia, depression, osttraumatic stress disorder (PTSD) (PTSD), bipolar disorder, Paranoid and so on. Based on the existing problems, the author designed a website-based expert system application. The design of this expert system uses the PHP programming language and the MySQL database uses genetic algorithms. Genetic algorithm is a method that can provide solutions in solving heuristic problems and is widely used for solving optimization problems. The genetic algorithm used is Certainty Factor. The results of the system test carried out on 20 experimental cases stated that $85 \%$ were in accordance with the results expected by expert data. The creation of the application is expected to make it easier to diagnose mental health disorders in someone.
\end{abstract}

Keywords: Website, Expert System, Genetics, Certainty Factor. 


\section{PENDAHULUAN}

\subsection{Latar Belakang}

Gangguan kesehatan mental (Mental Health Disorder) yaitu salah satu syndrome ataupun pola perilaku psikologi seseorang yang akan menyebabkan ketidakmampuan saat melakukan pekerjaan. Karena beragam kesulitan dan dilema yang muncul, banyaknya masalah yang tidak dapat dihadapi seseorang dalam kehidupan dapat mengganggu jaringan saraf otak manusia dan menyebabkan penyakit mental. Tingkat psikologis seseorang tergantung pada pengalaman emosional, perilaku, lingkungan maupun latar belakang pendidikan keluarga.

Akibat ketidakseimbangan antara jumlah penderita gangguan mental dengan jumlah dokter spesialis gangguan mental, banyak penderita gangguan mental harus menunggu lama untuk mendapatkan dokter spesialis. Selain itu, berkonsultasi dengan dokter spesialis penderita penyeakit gangguan keshatan mental juga perlu membayar biaya yang cukup mahal. Solusi yang tepat untuk mendiagnosa gejala awal gangguan mental adalah menggunakan sistem pakar dan algoritma genetika. Suatu populasi individu dikelola kemudian mendeskripsikan kandiadat solusi suatu optimasi kesehatan mental pada seseorang adalah konsep dasar algoritma genetika ini. Sistem ini dibuat bertujuan mengetahui nilai optimal dari berbagai macam keluhan gangguan kesehatan mental dan menganalisa karateristik metode algoritma genetika. Pemilihan metode algoritma genetika dalam hal ini berdasarkan penelitian terdahulu yang menunjukkan presentase keakuratan metode ini cukup tinggi.

Pada penelitian sebelumnya metode algoritma genetika dan sistem pakar digunakan untuk membuat aplikasi yang diharapkan dapat mempromosikan distribusi atau penyesuaian pola makan balita dan membantu balita tumbuh dan berkembang lebih baik [1]. Kemudian pada penelitian lain dibuatnya sistem pada android untuk mengenali berbagai macam penyait yang dikeluhkan ibu hamil, dan cara meminimalisir perasaan khawatir yang tidak perlu selama kehamilan, menghindari komplikasi berbagai penyakit, dan meningkatkan kesehatan ibu dan bayi [2]. Pada penelitian selanjutnya, pengimplemetasian algoritma genetika dengan merancang aplikasi smartphone yang dapat memprediksi buta warna. Aplikasi ini dapat membantu masyarakat untuk memprediksi buta warna dengan mudah [3]. Kemudian menerapkan algoritma genetika pada penelitian lain untuk memprediksi fertilitas (kesuburan) [4]. Berikutnya penelitian tentang pengimplentasian algoritma genetika pada AHP dan optimasi model topsis untuk menentukan pengisian bibit ayam broiler yang layak [5]. Kemudian peneliatan selanjutnya untuk mengimplementasikan algoritma genetika yang diterapkan dengan algoritma k-nearst neighbor agar dapat memaksimalkan tingkat akurasi klasifikasi pada penyakit tulang belakang [6]. Penelitian selanjutnya yaitu prediksi hepatitis dengan optimasi algoritma C4.5 menggunakan algoritma genetika [7]. Kemudian pada penelitian lainnya, untuk mendeteksi diabetes dini dengan algoritma neural network berbasis algoritma genetika. Pada penelitian ini peneliti melakukan optimasi model neural network dengan menerapkan algoritma genetika untuk mencari nilai parameter yang optimal pada model neural network [8]. Berkaitan dengan penelitian sebelumnya yang penggunaan algoritma neural network berbasis algoritma genetika lalu peneliti juga menerapkannya pada prediksi penyakit kanker pada payudara [9]. Penelitian selanjutnya menggunakan algoritma Bayes pada sistem aplikasi diagnosa gangguan kesehatan mental pada anak. Penelitian Metode Bayes berfungsi untuk mendiagnosa penyakit gangguan mental pada anak-anak berdasarkan dengan gejala yang dimiliki pasien terduga [10]. 


\section{METODE PENELITIAN}

\subsection{Sistem Pakar}

Sistem pakar adalah suatu sistem yang berusaha menerapkan pengetahuan manusia ke dalam komputer agar komputer tersebut dapat menyelesaikan masalah seperti yang biasa dilakukan oleh para ahli. Tujuan utama sistem pakar adalah untuk meniru pekerjaan para ahli untuk memecahkan berbagai masalah tertentu. Sistem pakar bahkan dapat memungkinkan orang biasa untuk memecahkan masalah kompleks yang tidak dapat diselesaikan tanpa bantuan ahli [11].

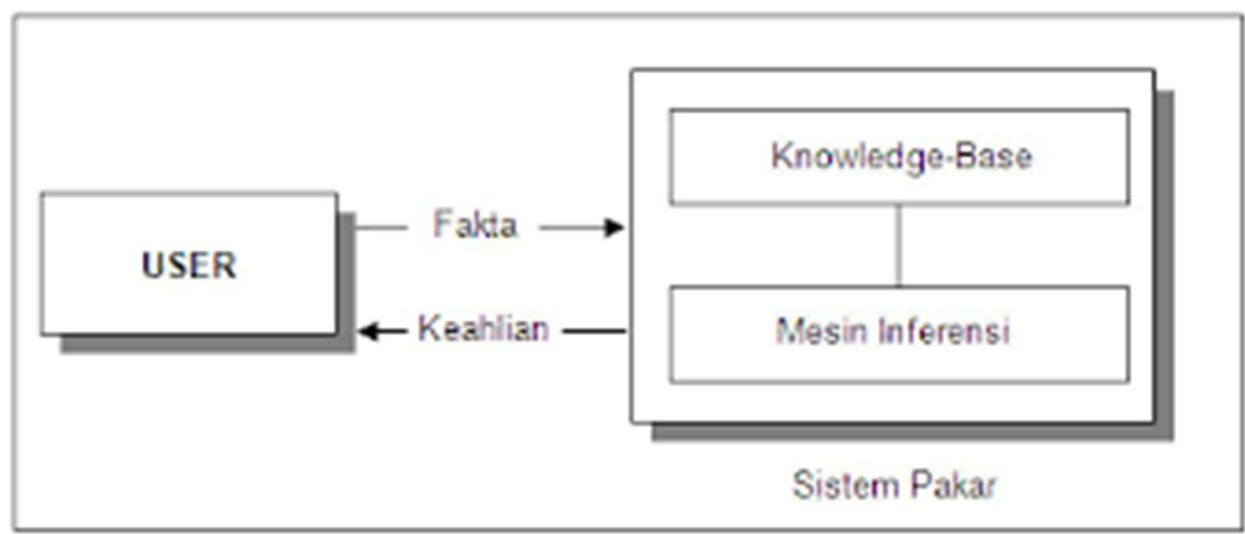

Gambar 1. Fungsi Sistem Pakar

\subsection{Algoritma Genetika}

Penelitian yang dilakukan oleh John Holland di Universitas Michigan, Amerika Serikat pada tahun 1975 lalu dipopolerkan oleh David Goldberg, yang menjadi muridnya. Terinspirasi pada prinsip genetika dan seleksi alam (teori evolusi Darwin). Dapat disimpulkan pada teori ini, di dalam alam terdapat persaingan antar mahkluk yang memperebutkan sumber daya alam, dimana mahkluk yang lebih kuat mengalahkan yang lemah.

Berikut adalah hal-hal yang harus diperhatikan dalam Algoritma Genetika adalah:

1. Menjelaskan definisi individu, definisi individu di sini merupakan solusi dari berbagai masalah yang ada.

2. Menjelaskan definisi nilai fitness, nilai fitness adalah ukuran baik atau tidaknya sebuah solusi yang didapat.

3. Menetapkan proses pembangkitan populasi awal.

4. Menetapkan proses seleksi yang akan digunakan.

5. Menetapkan proses perkawinan silang (crossover) dan mutasi gen.

David Goldberg merupakan tokoh pertama yang mencetuskan siklus algoritma genetika. Siklus diawali dari membentuk popilasi awal dengan cara acak, selanjutnya proses penghitungan nilai fitness-nya dari masing-masing individu. Proses selanjutnya yaitu melakukan penyeleksian individu yang terbaik, kemudian melakukan perkawinan menyilang lalu dilanjutkan melalui pemrosesan mutasi hingga terbentuknya populasi terbaru. Selain itu, populasi yang baru ini akan melewati siklus yang sama seperti populasi terdahulunya. Proses seperti ini akan berlanjut hingga generasi ke- $\mathrm{n}$ [3]. 


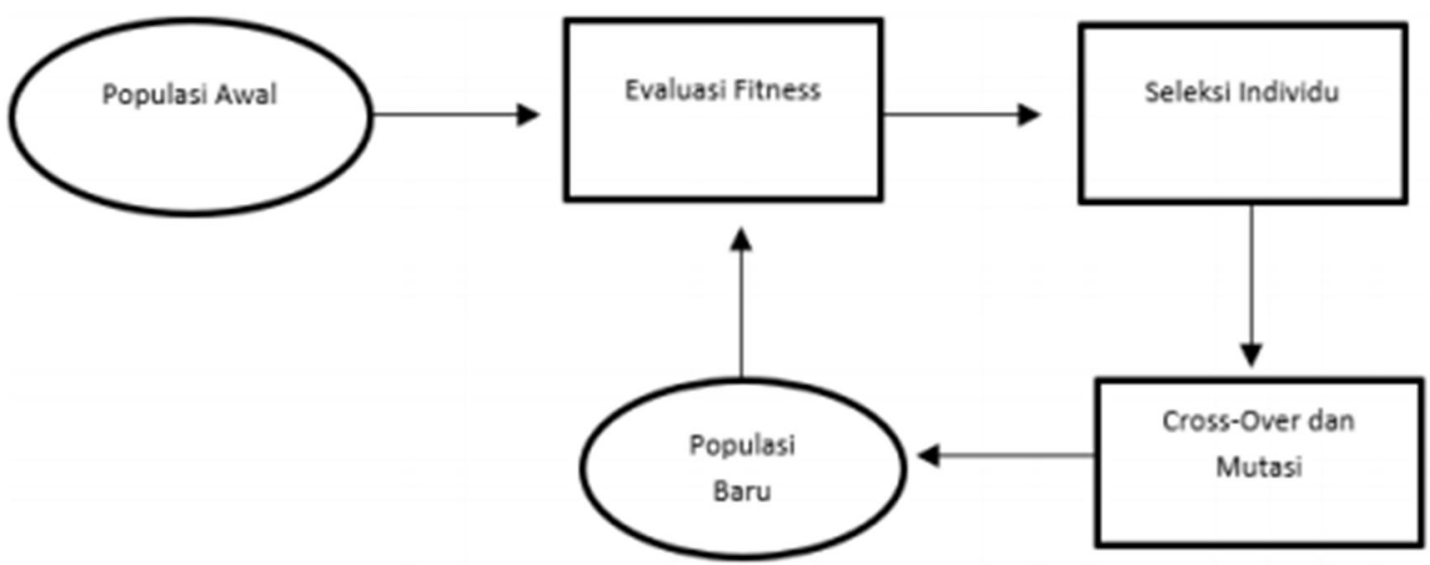

Gambar 2. Siklus Algoritma Genetika Diperkenalkan David Goldberg

\subsection{Metode Certanity Factor}

Certanity factor (Faktor kepastian) yaitu hasil dari nilai parameter klinis pada MYCIN yang dapat digunakan sebagai petunjuk dalam besarnya kepastian dan kepercayaan terhadap suatu fakta, dimana Shortliffe Buchanan memperkenalkan hal ini pada saat pembuatan MYCIN. Nilai terhadap suatu data yang diasumsikan melalui tingkat keyakinan seorang pakar dalam penggunaan Certanity factor.

dengan:

$$
\mathrm{CF}[\mathrm{H}, \mathrm{E}]=\mathrm{MB}[\mathrm{H}, \mathrm{E}]-\mathrm{MD}[\mathrm{H}, \mathrm{E}]
$$

$\mathrm{CF}[\mathrm{H}, \mathrm{E}]=$ Certainty Factor dari hipotesis $\mathrm{H}$ yang dipengaruhi oleh indikasi E. Besarnya $\mathrm{CF}$ berkisar antara -1 hingga 1 . Nilai -1 menampilkan ketidakpercayaan seutuhnya, sebaliknya nilai 1 menampilkan keyakinan seutuhnya.

$\mathrm{MB}[\mathrm{H}, \mathrm{E}]=$ Skala peningkatan kepercayaan terkait dengan Hipotesis $\mathrm{H}$ dipengaruhi oleh gejala E.

$\mathrm{MD}[\mathrm{H}, \mathrm{E}]=$ Skala peningkatan kepercayaan terkait dengan Hipotesis $\mathrm{H}$ dipengaruhi oleh gejala E.

Certaimty Factor sebagai referensi tunggal

$$
\mathrm{CF}[\mathrm{H}, \mathrm{E}] 1=\mathrm{CF}[\mathrm{H}] * \mathrm{CF}[\mathrm{E}]]
$$

Certainty Factor memiliki 2 nilai, sebagai berikut:

1. Nilai certainty factor suatu aturan yang nilainya tergantung kepada aturan-aturan yang nilainya diberikan oleh seorang ahli(pakar).

2. Nilai certainty factor yang diberi oleh pengguna lalu diwakili tingkat kepercayaan dari referensi (seperti kondisi, karakteristik, fenomena) dari pengalaman pengguna.

Dalam sistem pakar untuk mendiagnosis gangguan mental ini, nilai ketidakpercayaan dapat diabaikan bernilai 0 . Nilai CF diberikan untuk setiap gejala penyakit penyerta, sehingga setiap gejala mendapatkan nilai $\mathrm{CF}$ yang banyak. Untuk menetapkan nilai akhir $\mathrm{CF}$ dalam mendiagnosa, penggunaan rumus $\mathrm{CF}$ paralel seperti dibawah ini:

Keterangan:

$$
\mathrm{CF}[\mathrm{h}, \mathrm{e} 1 \wedge \mathrm{e} 2]=\mathrm{CF}[\mathrm{h}, \mathrm{e} 2] .(1-\mathrm{CF}[\mathrm{h}, \mathrm{e} 1]) .
$$

$\mathrm{CF}\left[\mathrm{h}, \mathrm{e} 1^{\wedge} \mathrm{e} 2\right]=$ Faktor kepastian paralel

$\mathrm{CF}[\mathrm{h}, \mathrm{e} 1]=$ Skala kepercayaan berdasarkan hipotesis $\mathrm{h}$, apabila diberi evidence e pertama (berkisar 0 sampai 1)

$\mathrm{CF}[\mathrm{h}, \mathrm{e} 2]=$ Skala kepercayaan berdasarkan hipotesis $\mathrm{h}$, apabila diberi evidence e kedua (berkisar 0 sampai 1) 
Pada penerapannya, $\mathrm{CF}(\mathrm{H}, \mathrm{E})$ adalah nilai kepastian yang diberikan dari pakar berdasarkan aturan, dan $\mathrm{CF}(\mathrm{E}, \mathrm{e})$ adalah nilai kepercayaan yang diberikan oleh pengguna terhadap gejala yang dialaminya. Saat mendiagnosis suatu penyakit, kemungkinan beberapa aturan menghasilkan hipotesis, dan satu hipotesis menjadi bukti lain dari aturan, oleh karena itu, perlu untuk menghitung gejala $\mathrm{CF}$ sebanyak mungkin berdasarkan input pengguna program.

Diagram alir (flowchart) metode faktor kepastian yang menggambarkan proses perhitungan diagnosis. Langkah pertama pasien harus memilih gejala yang dirasakan, kemudian sistem memproses gejala yang dipilih menggunakan perhitungan $\mathrm{CF}$ untuk memproses gejala yang dipilih, kemudian pasien akan dapat menemukan diagnosis hasil penyakit dan pilihan pengobatan. Pada gambar 3 dijelaskan proses prosedur diagnosis menggunakan metode faktor kepastian.

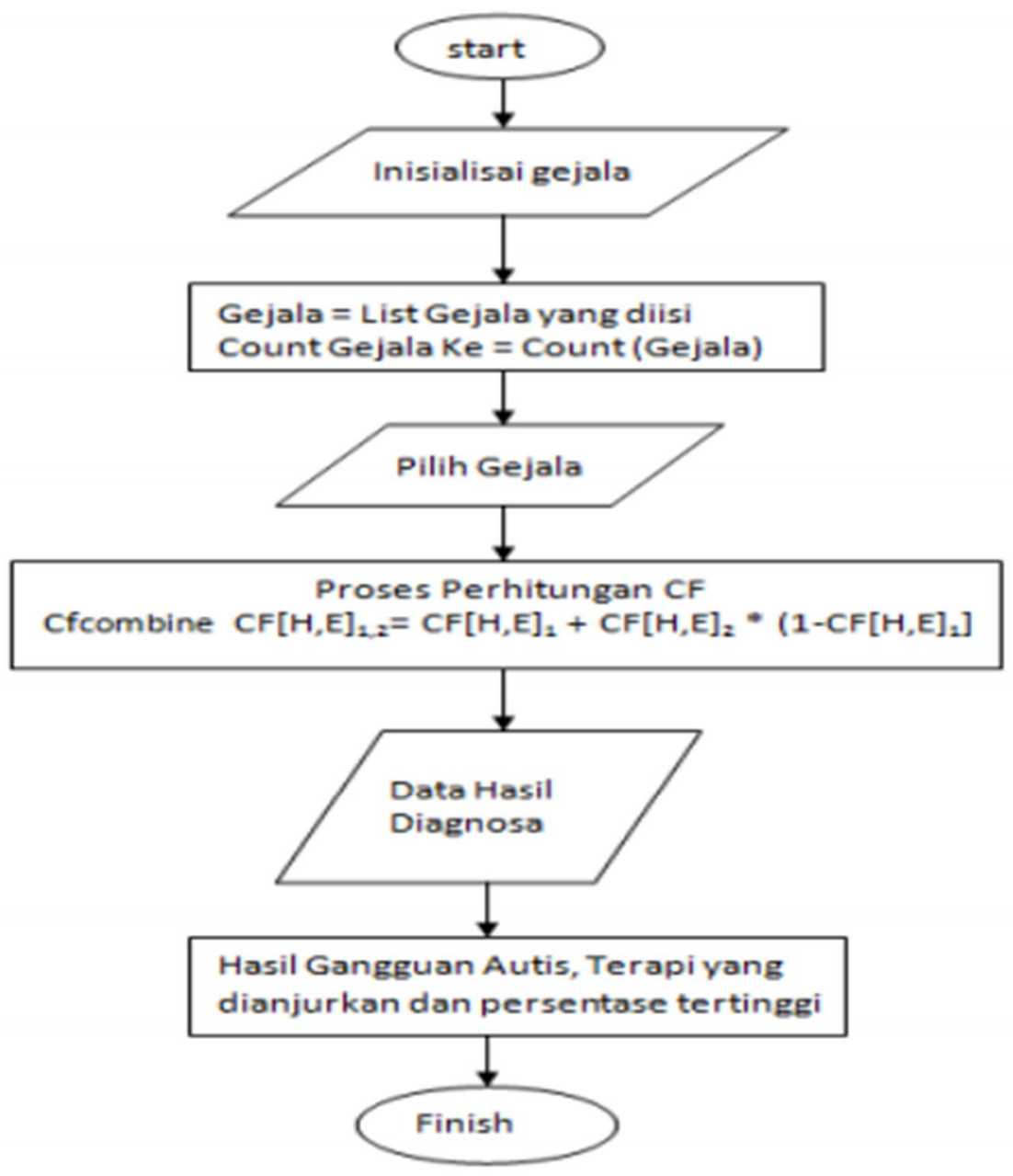

Gambar 3. Flowchart Metode Certainty Factor

\subsection{Tahapan Penelitian}

Tahapan ini merupakan proses identifikasi masalah yang dilakukan untuk mendapatkan analisa kebutuhan. Masalah yang diidentifikasi pada penelitian ini adalah bagaimana melakukan diagnosa pada gangguan kesehatan mental dan sistem pakar berbasis website dengan Algoritma Genetika meliputi: 
1. Analisis kebutuhan sistem pada tahap ini melakukan proses pencarian kebutuhan sistem atau software terkait kebutuhan user. Setelah itu sistem akan mengolah hasil klasifikasi yang sesuai berdasarkan hasil optimasi yang dilakukan oleh Algoritma genetika.

2. Analisis Kebutuhan Hardware Perangkat keras yang digunakan yaitu sebuah personal komputer, untuk mengoperasikan sistem optimasi.

3. Analisis Kebutuhan Software Perangkat lunak yang digunakan yaitu Mysql sebagai database server. Untuk menampilkan hasil dari sistem tersebut menggunakan Browser yang tersedia dan PHP digunakan untuk bahasa pemrograman script sederhana yang diguakan untuk pemrosesan HTML Form didalam halaman web.

\subsection{Metode Pengumpulan Data}

Melakukan pengumpulan bermacam-macam data agar dapat memperoleh informasi yang dibutuhkan untuk mencapai tujuan yang diharpkan dari penelitian ini. Penelitian ini melakukan pengumpulan data melalui penelitian kepustakaan dan wawancara. Penelitian kepustakaan merupakan suatu teknik mengumpulkan sebuat data lalu dilanjutkan dengan proses mencari informasi dalam buku, jurnal dan dokumen lain, yang bertujuan untuk membentuk landasan teori. Dalam penelitian ini dilakukan pencarian terhadap berbagi buku higga jurnal referensi dalam pengembangan sistem yang dibuat.

\subsection{Perancangan Sistem}

Tahapan ini membuat desain pada rancangan antar muka user pada saat melakukan login. Selanjutnya masuk ke sistem untuk mendiagnosa gangguan kesehatan mental ini berupa sebuah optimasi dari algoritma genetika. Pada tahap ini pula akan dijelaskan tentang cara kerja sistem.

\subsection{Pengujian Sistem}

Tahapan ini melakukan evaluasi kinerja aplikasi untuk memastikan bahwa fitur yang disertakan dalam sistem berfungsi seperti apa yang diharapkan penulis.

\section{HASIL DAN PEMBAHASAN}

\subsection{Basis Pengetahuan}

Pentingnya basis pengetahuan bagi sistem pakar. Basis pengetahuan diperoleh dari berbagai pengetahuan dan juga fakta yang diperoleh dengan proses wawancara dari para ahli dan referensi lain (seperti, jurnal, buku, dll). Beberapa fakta tercantum ditunjukan pada tabel 1 dibawah ini:

\begin{tabular}{cl}
\hline & \multicolumn{2}{c}{ Tabel 1. Data Penyakit } \\
\hline Id Penyakit & \multicolumn{1}{c}{ Nama Penyakit } \\
\hline P1 & Skizofrenia \\
P2 & Post Traumatic Stress Disorder (PTSD) \\
P3 & Depresi \\
P4 & Bipolar \\
P5 & Paranoid \\
\hline
\end{tabular}


Pada tabel 1 merupakan data jenis penyakit kesehatan mental. Masing-masing memiliki gejala. Gejala yang ditimbulkan di setiap jenis penyakit ada yang sama ada juga yang berbeda. Data gejala akan ditampilkan pada tabel 2 dibawah ini:

\begin{tabular}{ll}
\hline & \multicolumn{1}{c}{ Tabel 2. Data Gejala } \\
\hline Id Gejala & Gejala \\
\hline G1 & Sulit tidur \\
G2 & Mendengar suara aneh \\
G3 & Sering/mudah menangis \\
G4 & Kehilangan minat untuk melakukan aktivitas \\
G5 & Emosi menjadi datar \\
G6 & Ingatan terganggu \\
G7 & Menjauh dari lingkungan sosial \\
G8 & Pikiran dan berbicara kacau \\
G9 & Rasa Takut dan khawatir berlebihan \\
G10 & Mimpi Buruk \\
G11 & Sering merasa sedih \\
G12 & Mempercayai sesuatu yang tidak nyata \\
G13 & Sulit mengendalikan emosi \\
G14 & Diliputi perasaan bersalah berlebihan \\
G15 & Perasaan bermusuhan \\
G16 & Menghindari sebuah tempat/objek \\
G17 & Kehilangan Motivasi \\
G18 & Sering cemas \\
G19 & Moody \\
G20 & Perasaan putus asa \\
G21 & Kurangnya daya ingat \\
G22 & Bicara terlalu cepat \\
G23 & Gangguan pernafasan \\
G24 & Gerakan tubuh dan pikiran yang lambat \\
\hline &
\end{tabular}

Pada tabel 2 merupakan data gejala yang dirasakan penderita penyakit kesehatan mental (Mental Health Disorder). Gejala diatas tidak semuanya dirasakan oleh setiap jenis penyakit kesehatan mental (Mental Health Disorder). Ada yang hanya dirasakan oleh beberapa jenis penyakit saja. Gejala yang dirasakan memang hampir sama di semua jenis penyakit hepatitis, tetapi ada yang lebih spesifik ke jenis penyakitnya.

Tabel 3. Data Aturan

\begin{tabular}{|c|c|c|c|c|}
\hline No & Penyakit & & Gejala & Bobot \\
\hline 1 & Skizofrenia & & Kesulitan tidur & 0.2 \\
\hline 2 & Skizofrenia & & Mendengar suara aneh & 0.3 \\
\hline 3 & Skizofrenia & & Emosi menjadi datar & 0.6 \\
\hline 4 & Skizofrenia & & Menjauh dari lingkungan sosial & 0.2 \\
\hline 5 & Skizofrenia & & Pikiran dan berbicara kacau & 0.1 \\
\hline 6 & Skizofrenia & & Mempercayai sesuatu yang tidak nyata & 0.8 \\
\hline 7 & $\begin{array}{ll}\text { Post } & \text { Traumatic } \\
\text { Disorder (PTSD) }\end{array}$ & Stress & Kesulitan tidur & 0.4 \\
\hline 8 & Traumatic & Stress & Kehilangan minat untuk melakukan aktivitas & 0.2 \\
\hline
\end{tabular}

Daniel, et., al [Sistem Pakar Untuk Mendiagnosa Gangguan Kesehatan Mental Menggunakan Algoritma Genetika 


\begin{tabular}{|c|c|c|c|c|}
\hline & Disorder (PTSD) & & & \\
\hline 9 & $\begin{array}{l}\text { Post } \quad \text { Traumatic } \\
\text { Disorder (PTSD) }\end{array}$ & Stress & Ingatan terganggu & 0.5 \\
\hline 10 & $\begin{array}{l}\text { Post } \quad \text { Traumatic } \\
\text { Disorder (PTSD) }\end{array}$ & Stress & Rasa Takut dan khawatir berlebihan & 0.1 \\
\hline 11 & $\begin{array}{l}\text { Post } \quad \text { Traumatic } \\
\text { Disorder (PTSD) }\end{array}$ & Stress & Mimpi Buruk & 0.4 \\
\hline 12 & $\begin{array}{l}\text { Post } \quad \text { Traumatic } \\
\text { Disorder (PTSD) }\end{array}$ & Stress & Sulit mengendalikan emosi & 0.4 \\
\hline 13 & $\begin{array}{ll}\text { Post } & \text { Traumatic } \\
\text { Disorder (PTSD) }\end{array}$ & Stress & Menghindari sebuah tempat/objek & 0.2 \\
\hline 14 & Depresi & & Kesulitan tidur & 0.5 \\
\hline 15 & Depresi & & Kehilangan minat untuk melakukan aktivitas & 0.2 \\
\hline 16 & Depresi & & Sering merasa sedih & 0.6 \\
\hline 17 & Depresi & & Diliputi perasaan bersalah berlebihan & 0.1 \\
\hline 18 & Depresi & & Perasaan putus asa & 0.6 \\
\hline 19 & Depresi & & Menghindari sebuah tempat/objek & 0.4 \\
\hline 20 & Bipolar & & Sering/mudah menangis & 0.2 \\
\hline 21 & Bipolar & & Diliputi perasaan bersalah berlebihan & 0.6 \\
\hline 22 & Bipolar & & Kehilangan Motivasi & 0.3 \\
\hline 23 & Bipolar & & Moody & 0.8 \\
\hline 24 & Bipolar & & Kurangnya daya ingat & 0.5 \\
\hline 25 & Bipolar & & Bicara terlalu cepat & 0.2 \\
\hline 26 & Bipolar & & Mempercayai sesuatu yang tidak nyata & 0.1 \\
\hline 27 & Paranoid & & Menjauh dari lingkungan sosial & 0.3 \\
\hline 28 & Paranoid & & Rasa Takut dan khawatir berlebihan & 0.6 \\
\hline 29 & Paranoid & & Perasaan bermusuhan & 0.1 \\
\hline 30 & Paranoid & & Sering cemas & 0.1 \\
\hline 31 & Paranoid & & Gangguan Pernafasan & 0.4 \\
\hline 32 & Paranoid & & Gerakan tubuh dan pikiran yang lambat & 0.2 \\
\hline
\end{tabular}

Tabel 3 merupakan data aturan yang menghubungkan antara data penyakit dan data gejala. Pada data aturan masing-masing gejala setiap penyakit memiliki nilai bobot. Nilai bobot disini antara 0-1, sesuai dengan tingkat kemungkinan gejala di setiap penyakit. Data penyakit memiliki beberapa gejala yang memiliki kesamaan di setiap jenis penyakit dan juga memiliki perbedaan. Aturan ini nanti digunakan sebagai data utama yang akan diproses dengan gejala yang dimiliki oleh pengguna.

Logika aturan penyakit-gejala dibuat untuk menterjemahkan tabel-tabel keputusan pada diagnosa penyakit kesehatan mental menggunakan teknik Certainty Factor ditunjukkan seperti di tabel 4.

\begin{tabular}{cc}
\hline & Tabel 4. Logika Aturan Penyakit Gejala \\
\hline Aturan & Penyakit-Gejala \\
\hline A1 & IF G1 AND G2 AND G3 AND G5 AND G7 AND G8 AND G12 THEN A1 \\
A2 & IF G1 AND G4 AND G6 AND G9 AND G10 AND G13 AND G16 THEN A2 \\
A3 & IF G1 AND G4 AND G11 AND G14 AND G20 AND G16 THEN A3 \\
A4 & IF G3 AND G14 AND G17 AND G19 AND G21 AND G22 AND G12 THEN A4 \\
A5 & IF G7 AND G9 AND G15 AND G18 AND G23 AND G24 THEN A5 \\
\hline
\end{tabular}




\subsection{Contoh Perhitungan Manual Certainty Factor}

Perhitungan nilai Certainty Factor pada suatu diagnosa penyakit kesehatan mental sebagai berikut:

Jika dilakukannya diagnosis dengan menjawab semua pertanyaan yang dirasakan pengguna tentang gejala berikut. Pada step awal, pakar menetapkan nilai, langkah berikutnya dengan menentukan sebuah nilai pengguna.

\begin{tabular}{clc}
\hline \multicolumn{2}{c}{ Tabel 5. Tabel Nilai Pengguna } \\
\hline No. & Keterangan & Nilai Pengguna \\
\hline 1 & Tidak Mungkin & 0.2 \\
2 & Kemungkinan & 0.4 \\
3 & Kemungkinan Besar & 0.6 \\
4 & Hampir Pasti & 0.8 \\
5 & Pasti & 1 \\
\hline
\end{tabular}

Tabel 6. Contoh Perhitungan CF

\begin{tabular}{|c|c|c|c|}
\hline $\begin{array}{c}\text { Nama } \\
\text { Penyakit }\end{array}$ & Pertanyaan Gejala & CF Pakar & $\begin{array}{c}\text { CF } \\
\text { Pengguna }\end{array}$ \\
\hline \multirow[t]{6}{*}{ Skizofrenia } & Kesulitan tidur & 0.2 & 0.8 \\
\hline & Mendengar suara aneh & 0.3 & 0.2 \\
\hline & Emosi menjadi datar & 0.6 & 0.6 \\
\hline & Menjauh dari lingkungan sosial & 0.2 & 0.6 \\
\hline & Pikiran dan berbicara kacau & 0.1 & 1 \\
\hline & Mempercayai sesuatu yang tidak nyata & 0.8 & 0.2 \\
\hline \multirow{7}{*}{$\begin{array}{l}\text { Post } \\
\text { Traumatic } \\
\text { Stress } \\
\text { Disorder } \\
\text { (PTSD) }\end{array}$} & Kesulitan tidur & 0.4 & 0.8 \\
\hline & Kehilangan minat untuk melakukan aktivitas & 0.2 & 0.4 \\
\hline & Ingatan terganggu & 0.5 & 0.6 \\
\hline & Rasa Takut dan khawatir berlebihan & 0.1 & 0.4 \\
\hline & Mimpi Buruk & 0.4 & 0.2 \\
\hline & Sulit mengendalikan emosi & 0.4 & 0.6 \\
\hline & Menghindari sebuah tempat/objek & 0.2 & 0.4 \\
\hline \multirow[t]{6}{*}{ Depresi } & Kesulitan tidur & 0.5 & 0.8 \\
\hline & Kehilangan minat untuk melakukan aktivitas & 0.2 & 0.4 \\
\hline & Sering merasa sedih & 0.6 & 0.2 \\
\hline & Diliputi perasaan bersalah berlebihan & 0.1 & 0.6 \\
\hline & Perasaan putus asa & 0.6 & 0.4 \\
\hline & Menghindari sebuah tempat/objek & 0.4 & 0.4 \\
\hline \multirow[t]{7}{*}{ Bipolar } & Sering/mudah menangis & 0.2 & 0.4 \\
\hline & Diliputi perasaan bersalah berlebihan & 0.6 & 0.2 \\
\hline & Kehilangan Motivasi & 0.3 & 0.6 \\
\hline & Moody & 0.8 & 0.4 \\
\hline & Kurangnya daya ingat & 0.5 & 0.4 \\
\hline & Bicara terlalu cepat & 0.2 & 0.2 \\
\hline & Mempercayai sesuatu yang tidak nyata & 0.1 & 0.4 \\
\hline \multirow[t]{3}{*}{ Paranoid } & Menjauh dari lingkungan sosial & 0.3 & 0.6 \\
\hline & Rasa Takut dan khawatir berlebihan & 0.6 & 0.4 \\
\hline & Perasaan bermusuhan & 0.1 & 0.6 \\
\hline
\end{tabular}




\begin{tabular}{|l|l|l|l|}
\hline & Sering cemas & 0.1 & 0.4 \\
\cline { 2 - 4 } & Gangguan Pernafasan & 0.4 & 0.4 \\
\cline { 2 - 4 } & Gerakan tubuh dan pikiran yang lambat & 0.2 & 0.2 \\
\hline
\end{tabular}

Langkah selanjutnya, atuaran ini selanjutnya menghitung nilai dari CF. CF pakar dikalo dengan $\mathrm{CF}$ pasien dengan menggunkan rumus:

$\mathrm{CF}[\mathrm{H}, \mathrm{E}] 1=\mathrm{CF}[\mathrm{H}] * \mathrm{CF}[\mathrm{E}]]$

Terakhir merupakan langkah untuk mengkombinasikan nilai CF dari tiap-tiap aturan.

$$
\mathrm{CF}\left[\mathrm{h}, \mathrm{e} 1{ }^{\wedge} \mathrm{e} 2\right]-\mathrm{CF}[\mathrm{h}, \mathrm{e} 1]+\mathrm{CF}[\mathrm{h}, \mathrm{e} 2] .(1-\mathrm{CF}[\mathrm{h}, \mathrm{e} 1]) \ldots(3)
$$

Maka hasil dari perhitungan setiap data penyakit seperti dibawah ini:

1. Penyakit Skizofrenia

Tabel 7. Perhitungan Penyakit Skizofrenia

\begin{tabular}{|c|c|c|c|c|c|}
\hline CF & $\begin{array}{c}\text { KODE } \\
\text { GEJALA }\end{array}$ & $\begin{array}{c}\text { CF } \\
\text { RULE }\end{array}$ & $\begin{array}{c}\text { CF } \\
\text { USER }\end{array}$ & $\begin{array}{c}\text { CF } \\
(\mathbf{H , E})\end{array}$ & $\begin{array}{c}\text { CF } \\
\text { COMBINE }\end{array}$ \\
\hline 1 & 1 & 0.2 & 0.8 & 0.16 & 0 \\
\hline 2 & 2 & 0.3 & 0.2 & 0.06 & 0.21 \\
\hline 3 & 5 & 0.6 & 0.6 & 0.36 & 0.49 \\
\hline 4 & 7 & 0.2 & 0.6 & 0.12 & 0.55 \\
\hline 5 & 8 & 0.1 & 1 & 0.1 & 0.6 \\
\hline 6 & 12 & 0.8 & 0.2 & 0.16 & 0.66 \\
\hline
\end{tabular}

Kesimpulan Anda Mengalami SKIZOFRENIA memiliki tingkat keyakinan sistem $66 \%$. 2. Penyakit Post Traumatic Stress Disorder (PTSD)

Tabel 8. Perhitungan Penyakit Post Traumatic Stress Disorder

\begin{tabular}{|c|c|c|c|c|c|}
\hline CF & KODE & CF & CF & CF & CF \\
RULE & USER & (H,E) & COMBINE \\
\hline 1 & 1 & 0.4 & 0.8 & 0.32 & 0 \\
\hline 2 & 4 & 0.2 & 0.4 & 0.08 & 0.37 \\
\hline 3 & 6 & 0.5 & 0.6 & 0.3 & 0.56 \\
\hline 4 & 9 & 0.1 & 0.4 & 0.04 & 0.58 \\
\hline 5 & 10 & 0.4 & 0.2 & 0.08 & 0.61 \\
\hline 6 & 13 & 0.4 & 0.6 & 0.24 & 0.7 \\
\hline 7 & 16 & 0.2 & 0.4 & 0.08 & 0.72 \\
\hline
\end{tabular}

Kesimpulan Anda Mengalami POST TRAUMATIC STRESS DISORDER (PTSD) memiliki tingkat keyakinan sistem $72 \%$. 
3. Penyakit Depresi

Tabel 9. Perhitungan Penyakit Depresi

\begin{tabular}{|c|c|c|c|c|c|}
\hline CF & $\begin{array}{c}\text { KODE } \\
\text { GEJALA }\end{array}$ & $\begin{array}{c}\text { CF } \\
\text { RULE }\end{array}$ & $\begin{array}{c}\text { CF } \\
\text { USER }\end{array}$ & $\begin{array}{c}\text { CF } \\
\text { (H,E) }\end{array}$ & $\begin{array}{c}\text { CF } \\
\text { COMBINE }\end{array}$ \\
\hline 1 & 1 & 0.5 & 0.8 & 0.4 & 0 \\
\hline 2 & 4 & 0.2 & 0.4 & 0.08 & 0.45 \\
\hline 3 & 11 & 0.6 & 0.2 & 0.12 & 0.52 \\
\hline 4 & 14 & 0.1 & 0.6 & 0.06 & 0.55 \\
\hline 5 & 16 & 0.4 & 0.4 & 0.16 & 0.62 \\
\hline 6 & 20 & 0.6 & 0.4 & 0.24 & 0.71 \\
\hline
\end{tabular}

Kesimpulan Anda Mengalami DEPRESI memiliki tingkat keyakinan sistem $71 \%$.

4. Penyakit Bipolar

Tabel 10. Perhitungan Penyakit Bipolar

\begin{tabular}{|c|c|c|c|c|c|}
\hline CF & KODE & CF & CF & CF & CF \\
RULE & USER & (H,E) & COMBINE \\
\hline 1 & 3 & 0.2 & 0.4 & 0.08 & 0 \\
\hline 2 & 12 & 0.1 & 0.2 & 0.02 & 0.1 \\
\hline 3 & 14 & 0.6 & 0.6 & 0.36 & 0.42 \\
\hline 4 & 17 & 0.3 & 0.4 & 0.12 & 0.49 \\
\hline 5 & 19 & 0.8 & 0.4 & 0.32 & 0.65 \\
\hline 6 & 21 & 0.5 & 0.2 & 0.1 & 0.69 \\
\hline 7 & 22 & 0.2 & 0.4 & 0.08 & 0.71 \\
\hline
\end{tabular}

Kesimpulan Anda Mengalami BIPOLAR memiliki tingkat keyakinan sistem $71 \%$. 5. Penyakit Paranoid

Tabel 11. Perhitungan Penyakit Paranoid

\begin{tabular}{|c|c|c|c|c|c|}
\hline KF & $\begin{array}{c}\text { KODE } \\
\text { GEJALA }\end{array}$ & $\begin{array}{c}\text { CF } \\
\text { RULE }\end{array}$ & $\begin{array}{c}\text { CF } \\
\text { USER }\end{array}$ & $\begin{array}{c}\text { CF } \\
(\mathbf{H , E})\end{array}$ & $\begin{array}{c}\text { CF } \\
\text { COMBINE }\end{array}$ \\
\hline 1 & 7 & 0.3 & 0.6 & 0.18 & 0 \\
\hline 2 & 9 & 0.6 & 0.4 & 0.24 & 0.38 \\
\hline 3 & 15 & 0.1 & 0.6 & 0.06 & 0.42 \\
\hline 4 & 18 & 0.1 & 0.4 & 0.04 & 0.44 \\
\hline 5 & 23 & 0.4 & 0.4 & 0.16 & 0.53 \\
\hline 6 & 24 & 0.2 & 0.2 & 0.04 & 0.55 \\
\hline
\end{tabular}

Kesimpulan Anda Mengalami PARANOID memiliki tingkat keyakinan sistem $55 \%$. Dan hasil perhitungan keseluruhan selengkapnya dapat dilihat pada Tabel 12 
Tabel 12. Hasil Perhitungan

\begin{tabular}{|c|c|c|}
\hline NAMA PENYAKIT & PERSENTASE & RANKING \\
\hline Post Traumatic Stress Disorder (PTSD) & $72 \%$ & 1 \\
\hline Bipolar & $71 \%$ & 2 \\
\hline Depresi & $71 \%$ & 3 \\
\hline Skizofrenia & $66 \%$ & 4 \\
\hline Paranoid & $55 \%$ & 5 \\
\hline
\end{tabular}

Kesimpulan akhir anda mengalami post traumatic stress disorder (PTSD) dengan tingkat akurasi sebesar $72 \%$.

Solusi :

Psikoterapi Tujuan dari psikoterapi adalah membantu penderita paranoid mengontrol gejala yang muncul, meningkatkan kemampuan bersosialisasi dan membangun hubungan baik dengan orang lain, serta mengarahkan penderita pada perilaku yang positif. Salah satu jenis psikoterapi yang digunakan adalah terapi perilaku kognitif (CBT).

\subsection{Halaman Aplikasi}

a. Halaman Login Pengguna

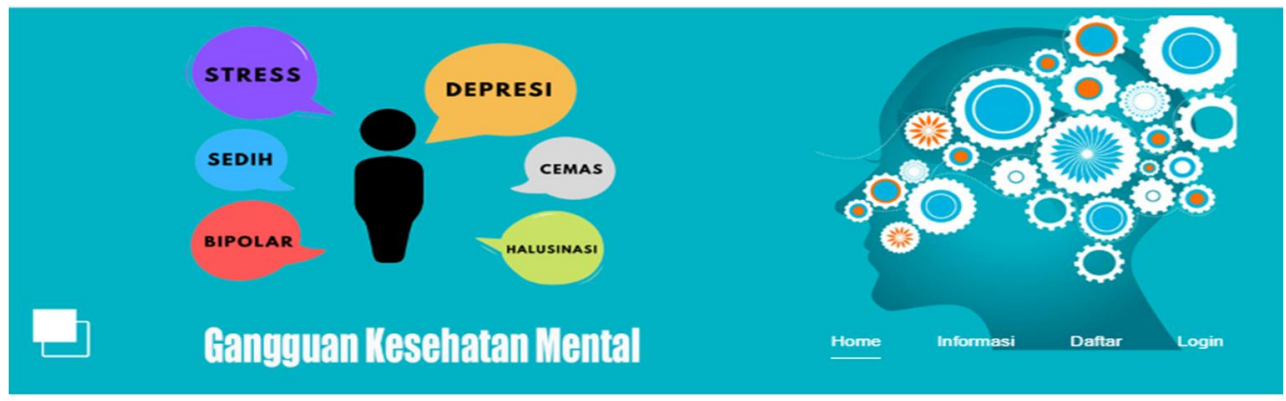

Login User
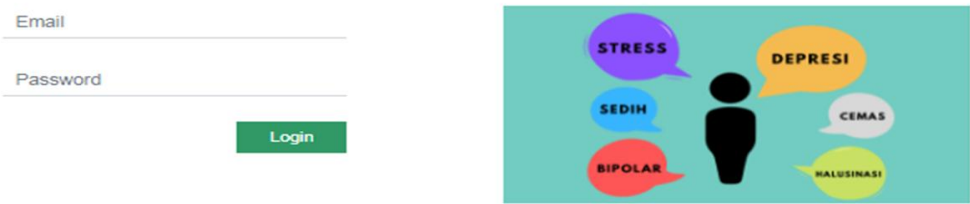

Gambar 4. Halaman Login Pengguna

Gambar 4 adalah tampilan login untuk pengguna. Setelah melakukan daftar maka pengguna masuk ke dalam aplikasi ini dengan login dengan memasukan email beserta password yang sudah didaftarkan. Jika sesuai dengan akun daftar maka pengguna bisa masuk dan melakukan diagnosa. 
b. Halaman Diagnosa Pengguna

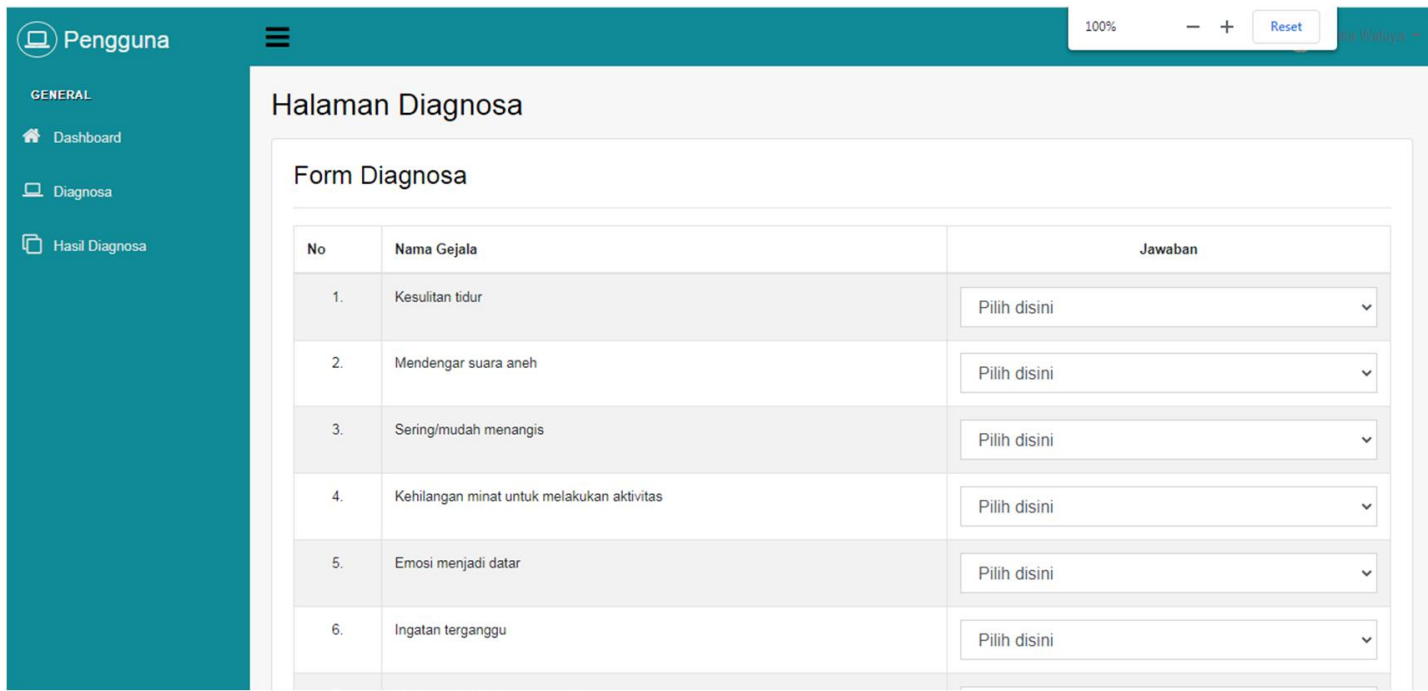

Gambar 5. Halaman Diagnosa Pengguna

Gambar 5 adalah halaman tampilan diagnosa pengguna. Pada halaman ini pengguna akan menjawab pilihan yang ada pada pertanyaan gejala sesuai dengan yang dialami. Gejala yang dipilih nantinya akan di proses menggunakan metode dan akan ditampilkan hasilnya oleh sistem.

c. Halaman Hasil Diagnosa

\begin{tabular}{rllcccc}
\hline 4. & 18 & 0.1 & 0.4 & 0.04 & 0.44 & 0.53 \\
\hline 5. & 23 & 0.4 & 0.4 & 0.16 & 0.55 \\
\hline 6. & 24 & 0.2 & 0.2 & 0.04 & 0.5
\end{tabular}

Kesimpulan Anda Mengalami PARANOID memiliki tingkat keyakinan sistem $55 \%$.

\begin{tabular}{|c|c|c|}
\hline NAMA PENYAKIT & PERSENTASE & RANKING \\
\hline POST TRAUMATIC STRESS DISORDER (PTSD) & $72 \%$ & 1 \\
\hline BIPOLAR & $71 \%$ & 2 \\
\hline DEPRESI & $71 \%$ & 3 \\
\hline SKIZOFRENIA & $66 \%$ & 4 \\
\hline PARANOID & $55 \%$ & 5 \\
\hline \multicolumn{3}{|c|}{$\begin{array}{l}\text { KESIMPULAN AKHIR ANDA MENGALAMI POST TRAUMATIC STRESS DISORDER (PTSD) DENGAN TINGKAT AKURASI SEBESAR } 72 \text { \%. } \\
\text { USI : } \\
\text { oterapi Tujuan dari psikoterapi adalah membantu penderita paranoid mengontrol gejala yang muncul, meningkatkan kemampuan bersosialisasi dan membangun hubungan } \\
\text { dengan orang lain, serta mengarahkan penderita pada perilaku yang positif. Salah satu jenis psikoterapi yang digunakan adalah terapi perilaku kognitif (CBT). }\end{array}$} \\
\hline
\end{tabular}

Gambar 6 adalah tampilan hasil diagnosa pengguna. Pada halaman ini pengguna bisa melihat kembali secara detail diagnosa yang telah dilakukan. Hasil diagnosa sendiri berisikan 
data id, tanggal dilakukan diagnosa, gejala yang dipilih serta nilai akurasi penyakit yang ditentukan oleh sistem.

\subsection{Hasil Pengujian}

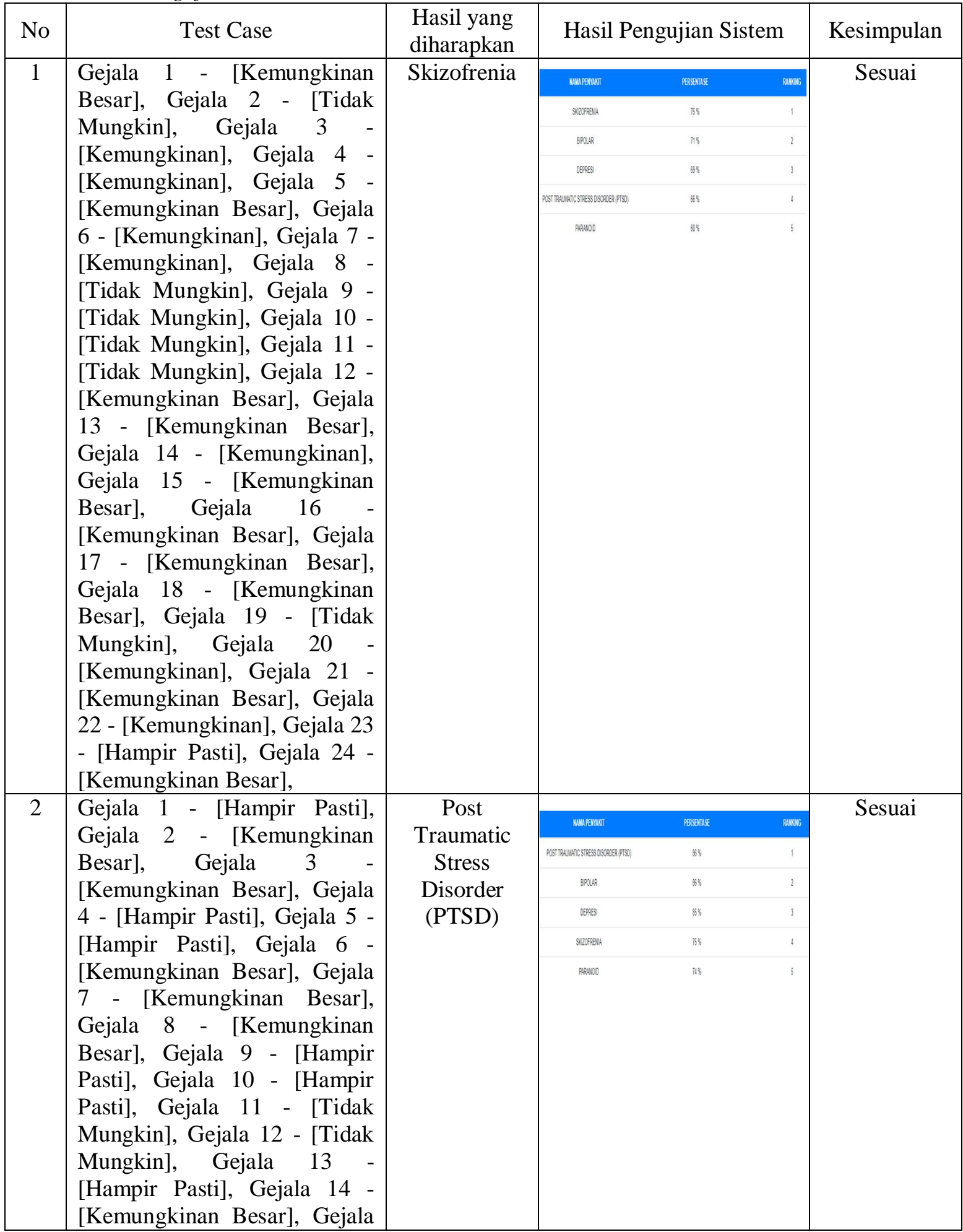

Daniel, et., al [Sistem Pakar Untuk Mendiagnosa Gangguan Kesehatan Mental Menggunakan Algoritma Genetika 


\begin{tabular}{|c|c|c|c|}
\hline & $\begin{array}{l}15-\text { [Kemungkinan Besar], } \\
\text { Gejala } 16-\text { [Hampir Pasti], } \\
\text { Gejala } 17-\text { [Kemungkinan } \\
\text { Besar], Gejala 18 - } \\
\text { [Kemungkinan Besar], Gejala } \\
19-\text { [Kemungkinan Besar], } \\
\text { Gejala } 20-\text { [Hampir Pasti], } \\
\text { Gejala } 21-\text { [Kemungkinan } \\
\text { Besar], Gejala 22 - } \\
\text { [Kemungkinan Besar], Gejala } \\
23-\text { - [Kemungkinan Besar], } \\
\text { Gejala } 24-\text { [Kemungkinan } \\
\text { Besar], }\end{array}$ & & \\
\hline 3 & Kasus 3 & Skizofrenia & Sesuai \\
\hline 4 & Kasus 4 & Bipolar & Sesuai \\
\hline 5 & Kasus 5 & Paranoid & Sesuai \\
\hline 6 & Kasus 6 & $\begin{array}{c}\text { Post } \\
\text { Traumatic } \\
\text { Stress } \\
\text { Disorder } \\
\text { (PTSD) }\end{array}$ & Sesuai \\
\hline 7 & Kasus 7 & Paranoid & Tidak Sesuai \\
\hline 8 & Kasus 8 & Paranoid & Sesuai \\
\hline 9 & Kasus 9 & $\begin{array}{c}\text { Post } \\
\text { Traumatic } \\
\text { Stress } \\
\text { Disorder } \\
\text { (PTSD) }\end{array}$ & Sesuai \\
\hline 10 & Kasus 10 & Bipolar & Sesuai \\
\hline 11 & Kasus 11 & Paranoid & Tidak Sesuai \\
\hline 12 & Kasus 12 & Paranoid & Sesuai \\
\hline 13 & Kasus 13 & $\begin{array}{c}\text { Post } \\
\text { Traumatic } \\
\text { Stress } \\
\text { Disorder } \\
\text { (PTSD) }\end{array}$ & Sesuai \\
\hline 14 & Kasus 14 & Skizofrenia & Sesuai \\
\hline 15 & Kasus 15 & Bipolar & Sesuai \\
\hline 16 & Kasus 16 & Skizofrenia & Sesuai \\
\hline 17 & Kasus 17 & Bipolar & Sesuai \\
\hline 18 & Kasus 18 & $\begin{array}{c}\text { Post } \\
\text { Traumatic } \\
\text { Stress } \\
\text { Disorder } \\
\text { (PTSD) }\end{array}$ & Tidak Sesuai \\
\hline 19 & Kasus 19 & Paranoid & Sesuai \\
\hline 20 & Kasus 20 & Paranoid & Sesuai \\
\hline
\end{tabular}


Pengujian sistem pakar diagnosa gangguan kesehatan mental dilakukan dengan menyamakan hasil proses menghitung hasil kasus baru pengguna dah dilakukan sistem berdasarkan data dari pakar. Dari hasil pengujian pada 20 kasus diatas, Ada 17 buah kasus yang sesuai dan 3 buah kasus tidak sesuai. Artinya ada $85 \%$ kasus sesuai juga $15 \%$ yang tidak sesuai.hasil yang ditampilkan oleh sistem sesuai dengan analisa pakar. Sehingga sistem ini bisa membantu dalam mendiagnosa gangguan kesehatan mental.

\section{KESIMPULAN}

Dapat disimpulkan dari pembuatan aplikasi sistem pakar ini dengan menggunakan metode faktor deterministik untuk mendiagnosis penyakit mental dapat membantu seseorang mendiagnosis jenis penyakit mental dengan gejala yang jelas tanpa pemeriksaan medis, dan memberikan solusi untuk diagnosisnya.

Total Nilai CF yang besar ditentukan pada bermacam-macam kecocokan dengan gejala juga hambatan dan besarnya nilai CF pada setiap aturan dalam aturan diagnosia. Nilai CF berada pada rentang 0 sampai 1 . Jika output $\mathrm{CF}$ mendekati 1 , maka nilai kepastiannya mendekati true. Selain itu, sistem dapat memperbarui data dan menambahkannya ke basis pengetahuan, termasuk data aturan dan data yang terkandung di dalamnya.

\section{SARAN}

Saran untuk penelitian ini adalah lebih meningkatkan tingkat persentase keyakinan dan akurasi pada hasil diagnosa gangguan kesehatan mental pada sistem pakar. Untuk menambahkan kasus baru pada data agar mampu mediagnosa dengan akurat.

\section{DAFTAR PUSTAKA}

[1] Adyatama, A. 2020, Rancang Bangun Aplikasi Terkait Pola Makan Terhadap Tumbuh Kembang Balita Menggunakan Algoritma Genetika dan Sistem Pakar Forward Chaining Berbasis Android, e-Proceeding of Engineering: Vol.7, No.1.

[2] Nafi, N. 2018, Sistem Penentuan Keluhan Ibu Hamil Dengan Algoritma Genetika, SEMINASKIT.

[3] Ridha, S. M. 2019, Implementasi Algoritma Genetika pada Perancangan Aplikasi Android Untuk Memprediksi Buta Warna, Jurnal Teknik Komputer, Vol. V No. 1

[4] Buani, P. 2016, Optimasi Algoritma Nä̈ve Bayes Dengan Menggunakan Algoritma Genetika Untuk Prediksi Kesuburan (Fertility), Jurnal Evolusi Vol. 4 No. 1.

[5] Mu'asyaroh, F. 2016, Implementasi Algoritma Genetika Dalam Optimasi Model Ahp dan Topsis Untuk Penentuan Kelayakan Pengisian Bibit Ayam Broiler di Kandang Peternak, Jurnal Teknologi Informasi dan Ilmu Komputer (JTIIK) Vol. 3, No. 4.

[6] Prasetio, T. R. 2018, Implementasi Algoritma Genetika pada K-Nearest Neighbours Untuk Klasifikasi Kerusakan Tulang Belakang, Jurnal Informatika, Vol.5 No.2. 
[7] Septiani, D. W. 2020, Optimasi Algoritma C4.5 Menggunakan Algoritma Genetika Untuk Prediksi Penyakit Hepatitis, Inti Nusa Mandiri VoL. 15. No. 1.

[8] Asri, P. 2018, Deteksi Dini Penyakit Diabetes Menggunakan Algoritma Neural Network Berbasiskan Algoritma Genetika, Jurnal Informatika: Jurnal Pengembangan IT (JPIT), Vol.03, No.03.

[9] Nurelasari, E. 2018, Penerapan Metode Metode Neural Network Berbasis Algoritma Genetika Untuk Prediksi Penyakit Kanker Payudara, Journal Speed - Sentra Penelitian Engineering dan Edukasi - Vol. 10 No. 3.

[10] Pujianto, A. 2016, Sistem Pakar Untuk Mendiagnosa Penyakit Mental pada Anak Menggunakan Algoritma Bayes, Seminar Nasional Teknologi Informasi dan Multimedia 2302-3805. 